\title{
Demand-supply of neurointerventionalists for endovascular ischemic stroke therapy
}

Osama O. Zaidat, MD, MS

Marc Lazzaro, MD Emily McGinley, MS Randall C. Edgell, MD Thanh Nguyen, MD Italo Linfante, $\mathrm{MD}$ Nazli Janjua, MD

Correspondence \& reprint requests to Dr. Zaidat: szaidat@mcw.edu

\section{ABSTRACT}

Objective: To estimate the needed workforce of trained neurointerventionalists (NIs) to perform endovascular therapy (ET) for eligible patients with acute ischemic stroke (AIS).

Method: Population and ischemic stroke incidence data were extracted with use of US Census and Centers for Disease Control and Prevention 2009 estimates. The annual "demand" is defined as the proportion of AIS patients who would meet inclusion criteria and clinical standards for ET. The "supply" is defined as the number of trained Nls and NIs in training. The "workforce" is the number of NIs needed to meet the demand (the number of eligible AIS patients) within an accessible geographic diameter. Data on NIs and NI fellowships were collected (Society of Neurointerventional Surgery [SNIS], Society of Vascular \& Interventional Neurology [SVIN], Concentric Medical, and Penumbra Inc.).

Results: The estimated number of Nls is close to 800 , practicing within a 50-mile radius of major metropolitan areas in the United States, covering more than $95 \%$ of the US population. Approximately $40 \mathrm{NI}$ fellows are graduating yearly from US training programs. In 5 years and 10 years, the number of NIs may reach 1,000 and 1,200, respectively. Currently, there are approximately 14,000 thrombectomy procedures performed in the United States each year. However, the percentage of AIS patients who may be eligible for ET in our estimation is $4 \%$ to $14 \%$, or about 25,000 to 95,000 patients. This means that cases will occur at a rate of 26 to 97 per year in 5 years, or 22 to 81 per year in 10 years, for each NI. Providing 24/7 AIS coverage requires 2 to 3 Nls per medical center, adding to the challenge of providing manpower without diluting experience in areas of lower population density.

Conclusion: The current and projected number of NIs would adequately supply the future need if the proportion of patients requiring AIS endovascular therapy increases. However, 2 to 3 NIs per comprehensive stroke center would be needed to provide 24/7 AIS therapy with a sufficient number of cases per NI. A tertiary stroke center model similar to the trauma model may provide the manpower solution without compromising the quality of care. Neurology ${ }^{\circledR} 2012 ; 79$ (Suppl 1):S35-S41

\section{GLOSSARY}

AIS = acute ischemic stroke; IMS = Interventional Management of Stroke; MELT = Middle Cerebral Artery Embolism Local Fibrinolytic Intervention Trial; $\mathbf{M E R C I}=$ Mechanical Embolus Removal in Cerebral Ischemia; $\mathbf{N I}=$ neurointerventionalist; NIHSS = NIH Stroke Scale; PROACT = Prolyse in Acute Cerebral Thromboembolism; SNIS = Society of Neurointerventional Surgery; SVIN = Society of Vascular \& Interventional Neurology; THRACE = Trial and Cost Effectiveness Evaluation of Intra-arterial Thrombectomy in Acute Ischemic Stroke.

Revascularization techniques of occluded cerebral arteries in ischemic brain tissue have demonstrated feasibility for acute ischemic stroke (AIS) in both animal models and humans. ${ }^{1,2}$ "Time is brain," and recovery of brain tissue is time dependent. Approximately 1.9 million neurons with 14 billion synapses are lost every minute in devascularized brain tissue. ${ }^{3}$ The Prolyse in Acute Cerebral Thromboembolism (PROACT) Trial and Middle Cerebral Artery Embolism Local Fibrinolytic Intervention Trial (MELT) have shown efficacy of intra-arterial therapy

From the Departments of Neurology (O.O.Z., M.L.), Neurosurgery (O.O.Z.), Radiology (O.O.Z.), and Biostatics/Epidemiology (E.M.), Medical College of Wisconsin \& Froedtert Hospital, Milwaukee; Department of Neurology (R.C.E.), St. Louis University, St Louis, MO; Department of Neurology (T.N.), Boston Medical Center, Boston, MA; Department of Neurology, Baptist Vascular Institute (I.L.), Miami, FL; Asia Pacific Comprehensive Stroke Institute (N.J.), Panoa, HI.

Go to Neurology.org for full disclosures. Disclosures deemed relevant by the authors, if any, are provided at the end of this article. 
with use of chemical fibrinolytics within 6 hours of symptom onset. ${ }^{4,5}$ Bridging therapy, following IV therapy with intra-arterial techniques, has proven its feasibility and safety and is being evaluated for efficacy in randomized prospective studies, the Interventional Management of Stroke (IMS III) trial and possibly the Trial and Cost Effectiveness Evaluation of Intra-arterial Thrombectomy in Acute Ischemic Stroke (THRACE) study. ${ }^{6,7}$ Penumbral imaging has shown that "imaging selected patients" would benefit from delayed revascularization up to 24 hours from onset of symptoms (imaging vs timing proponents). ${ }^{8-11}$

To achieve safe and effective delivery of endovascular therapy to AIS patients, an understanding of the availability of neurointerventionalists (NIs) and the demand for endovascular AIS therapy is important. The interrelationship between the supply of proficient NIs and the need for endovascular stroke therapy is complex. The highly specialized skills involved in AIS endovascular therapy demand a sufficient case volume to maintain skill level; however, this must be balanced against the risk of burnout from an overwhelming practice. Understanding the balance between neurointerventional availability and stroke demand is important for organized stroke system planning.

METHOD AND RESULTS Estimating the supply. The supply is the number of NIs trained according to Accreditation Council for Graduate Medical Education guidelines (www. acgme.org/acWebsite/downloads/RRC_progReq/422_endovascular_neuroradiology_01012008_u06102008.pdf, www.ACGME. org). Data on the number of NIs in the United States, number of centers performing endovascular intervention, and number of NI fellowship programs were obtained from Society of Neurointerventional Surgery (SNIS), Society of Vascular \& Interventional Neurology (SVIN), Concentric Medical Inc., and Penumbra Inc. The number of fellowship-trained NIs, estimated as per 2011, is close to 800 , according to SNIS senior and active member sources and SVIN active member sources. The trained NIs can be divided into approximately 600 neuroradiologists, 100 neurosurgeons, and 100 neurologists. In addition to the 800 practicing and trained NIs, at least every year there are close to 40 new NIs graduating across the country, which would make the number close to 1,000 in the next 5 years and close to 1,200 in the next 10 years.

Estimating the demand. The annual demand is defined as the proportion of AIS patients who would meet the inclusion criteria or clinical standards for endovascular therapy. This was estimated based on the following 3 methods. In the first method, a population-based approach was used by calculating the total number of all ischemic strokes in the United States from published annual incidence estimates by epidemiologic populationbased studies. Population and ischemic stroke incidence data were extracted with use of US census and Centers for Disease Control and Prevention data from 2009 estimates. ${ }^{12}$ To estimate the number of acute AIS patients eligible for endovascular therapy, we estimated the number of large-vessel occlusions from population-based AIS subtypes. American Heart Association/ American Stroke Association stroke statistics and published data on stroke mortality were used to estimate the stroke incidence. ${ }^{13-15}$ The second method was a clinical trial-based approach that relied on published prospective intra-arterial studies. This method was used to determine the proportion of patients enrolled from the number who were screened for endovascular AIS therapy trials. In the third method, a local and regional registry approach was used to estimate the number of AIS patients eligible for endovascular therapy, based on a single-center experience and regional published registries of admissions for AIS and the proportion of patients with severe stroke and largevessel disease.

Population- and epidemiology-based estimate. There are approximately 795,000 strokes every year in the United States; of these, only $85 \%$ to $87 \%$ are ischemic (i.e., about 675,000 are AIS). ${ }^{12-15}$ Based on US census data, the estimated US population is 312 million, ${ }^{12}$ and the incidence of all strokes (795,000/312 million) equals $0.26 \%$. Estimating the number of ischemic strokes at 675,000 translates to an ischemic stroke annual incidence of $0.22 \%$ (figure, A). This number $(0.22 \%)$ may be different if one considers the age-specific annual incidence of completed strokes from the Framingham Longitudinal Study. ${ }^{16}$ The findings showed that 1.67 million of the population aged 35 to 94 years may have ischemic and hemorrhagic strokes, of which 0.85 or 1.42 million would have ischemic stroke; however, the group between 35 and 85 years of age constitutes 54\% of the cases, or 766,800 . This brings the number of first-ever strokes closer to the American Stroke Association estimate. The question is, of the population first-ever strokes, what is the proportion that may be eligible for endovascular therapy?

Estimating the number of AIS cases requiring intra-arterial therapy necessitates considerable assumptions about the prevalence of large-vessel disease and the proportion of patients who would meet the endovascular therapy inclusion criteria. The prevalence of large-vessel disease, including cardioembolic stroke, is $27 \%$, according to a Northern Manhattan study. ${ }^{16}$ Estimating $27 \%$ of 675,000 results in a projected 182,250 largevessel strokes. In our experience, the percentage of patients with severe stroke (NIH Stroke Scale [NIHSS] score greater than 8 ) is an estimated $35 \%$, or about 63,788 (assuming one-third of these patients may meet all inclusion criteria for endovascular therapy, rather than the full 27\%). This seems to be an overestimate. The population- and epidemiology-based AIS endovascular demand would be about $9 \%$ to $27 \%$ (assuming all large-vessel occlusions meet treatment criteria-less likely-from among the total 675,000 annual ischemic strokes, or $\sim 60,750$ to 182,250 patients annually).

Estimates based on prospective acute stroke endovascular treatment studies. Table 1 shows prior prospective studies that screened thousands of AIS patients to enroll only a small percentage into endovascular therapy, ranging between $2 \%$ and $16 \%$ (mean, $6.1 \%$ ) of the screened patients. The data derived from these studies are limited by their mixed nature; some enrolled patients up to 3 hours from symptom onset (IMS I and II) and others up to 6 hours (PROACT I and II trials and MELT) 
Figure US maps depicting density of acute ischemic stroke patients eligible for endovascular ischemic stroke therapy, a reflection of the population density, and hospitals' ability to perform intra-arterial therapy

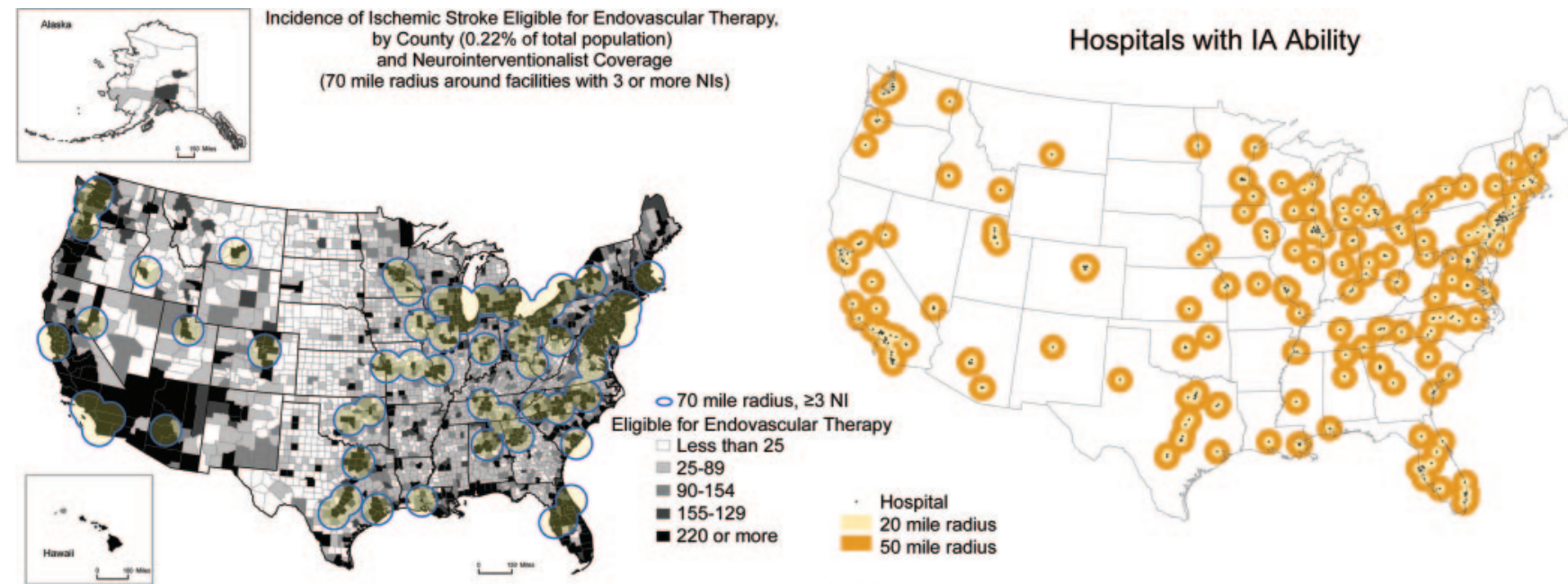

A

B

Hospitals with IA Ability: 1-2 Neurointerventionalists

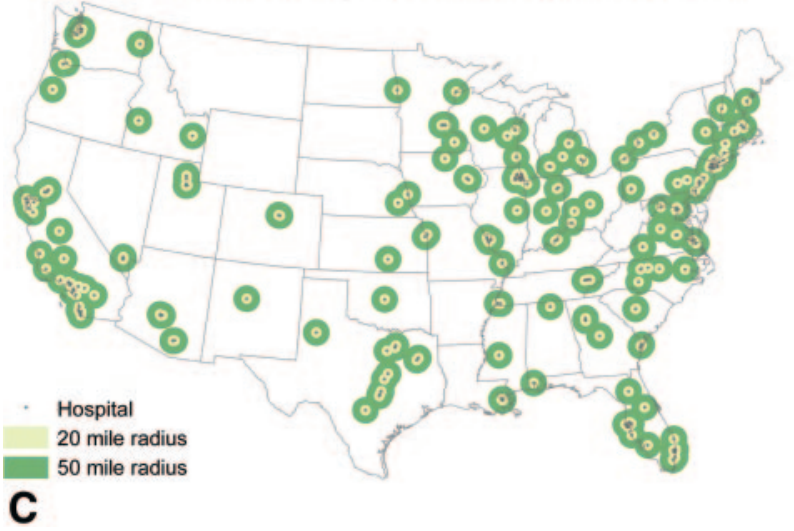

Hospitals with IA Ability: $\geq 3$ Neurointerventionalists

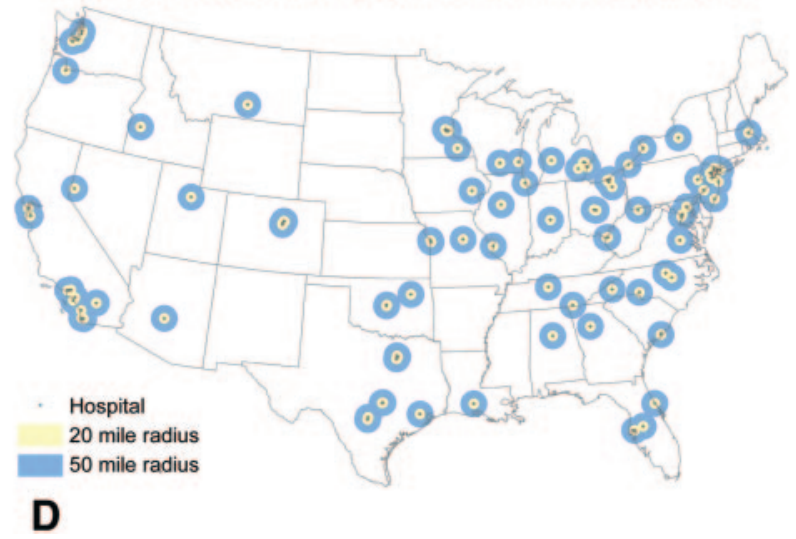

Maps were created with ArcGIS 9.3 (Esri, Redlands, CA), with use of state and county boundary files from Esri. Superimposed on the population density is coverage by fellowship-trained neurointerventionalists within 70 miles (A). The remaining maps demonstrate the presence of a least 1, 2, or 3 fellowshiptrained neurointerventionalists within 20 - and 50 -mile radii.

or 8 hours (Mechanical Embolus Removal in Cerebral Ischemia [MERCI] Trial, Multi-MERCI, and Penumbra). ${ }^{4-7,17-20}$ Table 2 summarizes all the prospective studies. Based on the screening data from prospective intra-arterial chemical and mechanical thrombectomy trials, the mean percentage of patients who were treated from those who were screened is $6.1 \% \pm 4.6 \%$ (1.5\% to $10.7 \%)$, or an annual volume of $\sim 43,000$ within a range of 11,000 to 75,000 .

Estimates based on acute ischemic stroke registries. In a study of why patients are excluded from acute stroke intervention, only $2.4 \%$ underwent intra-arterial thrombolysis. The reasons for exclusion included TIA in $14 \%$ of patients and improving neurologic deficit in $10 \%{ }^{21}$ In a recent study with use of a CT angiography database, 1,341 AIS patients underwent CT angiography on admission, and only 388 (28.9\%) had proximal vessel occlusion. ${ }^{22}$ No data are available regarding the severity of deficit, age distribution, or degree of parenchymal infarct of this cohort with largevessel occlusion. It is unlikely that all the large-vessel disease would meet the criteria for intra-arterial therapy. From the $28.9 \%$ with large-vessel occlusion in the CT angiography study, it is likely that $10 \%$ would be eligible for endovascular therapy, given that in the second described estimating method a small percentage of the screened patients were found eligible. It is likely that the other $18.9 \%$ would be excluded for other factors, such as mild clinical deficit, improving deficit, age, and comorbidities. In a different AIS registry, the NIHSS score was $<4$ for about $41 \%$ of the cohort, between 5 and 9 for $24 \%$, and $>24$ for almost $7 \%$, for a total of $72 \%$ potentially excluded due to NIHSS score alone..$^{23}$ This leaves about $28 \%$ with an NIHSS score between 10 and $24 .{ }^{23}$ If one-third of those with severe strokes are older than 85 years, then the estimate would be the same as in the Canadian study ( $18 \%$ of all stroke admissions), assuming every patient meets all other criteria for endovascular therapy, including arrival within time and no other medical exclusions. However, in this registry, only $0.7 \%$ of the patients were treated with intra-arterial thrombolysis within 6 hours, and 21\% were treated with IV fibrinolytic therapy.

In our hospital (Medical College of Wisconsin/Froedtert Hospital), of the 625 cases of ischemic stroke, the number treated last year with endovascular therapy was 64 , or $10.2 \%$ of all stroke admissions. Two of the patients we did not treat were randomized to receive IV thrombolytic therapy only in the IMS III trial. In this supplement, Zahuranec et al. review the work done by several stroke groups on AIS patients' arrival at the 


\begin{tabular}{|c|c|c|c|c|}
\hline \multirow{2}{*}{$\begin{array}{l}\text { Table } 1 \\
\text { Study }\end{array}$} & \multicolumn{4}{|c|}{$\begin{array}{l}\text { From AIS interventional studies, estimates of patients enrolled vs } \\
\text { screened for AIS endovascular therapy and crude estimates of } \\
\text { patients eligible for such therapy }\end{array}$} \\
\hline & & No. screened & $\begin{array}{l}\text { Type of occlusion: } \\
\text { no. enrolled }\end{array}$ & $\begin{array}{l}\text { Percentage of } \\
\text { enrolled or screened }\end{array}$ \\
\hline \multirow{4}{*}{\multicolumn{2}{|c|}{ PROACT I (1998) }} & All: 1,314 & MCA: 46 & 3.5 \\
\hline & & & All: 80 & 6.1 \\
\hline & & Arrived within 6 h: 927 & MCA: 46 & 5 \\
\hline & & & All: 80 & 9 \\
\hline \multirow{4}{*}{\multicolumn{2}{|c|}{ PROACT II (1999) }} & All: 12,323 & MCA: 180 & 1.5 \\
\hline & & & All: 241 & 2.0 \\
\hline & & Arrived within $6 \mathrm{~h}: 8,270$ & MCA: 180 & 2.2 \\
\hline & & & All: NA & 3.0 \\
\hline \multicolumn{2}{|l|}{ MERCI (2005) } & 1,809 & All: 151 & 8.4 \\
\hline \multicolumn{2}{|c|}{ Multi-MERCI (2008) } & 1,088 & All: 177 & 16.3 \\
\hline \multirow{2}{*}{\multicolumn{2}{|c|}{ MELT (2007) }} & All: NA & NA & NA \\
\hline & & Clinically eligible: 337 & 115 & 34 \\
\hline \multicolumn{2}{|c|}{ Penumbra (2009) } & 856 & 125 & 14.6 \\
\hline \multicolumn{2}{|l|}{ IMS I (2004) } & IMS I: 1,477 & 80 & 5.4 \\
\hline \multicolumn{2}{|l|}{ IMS II (2007) } & IMS II: 3,602 & 81 & 2.3 \\
\hline \multicolumn{4}{|c|}{ Mean (SD); 95\% Cl } & $6.1(4.6) ; 3.4-8.8$ \\
\hline
\end{tabular}

Abbreviations: $\mathrm{AIS}=$ acute ischemic stroke; $\mathrm{Cl}=$ confidence interval; IMS = Interventional Management of Stroke; MCA = middle cerebral artery; MELT = Middle Cerebral Artery Embolism Local Fibrinolytic Intervention Trial; MERCI = Mechanical Embolus Removal in Cerebral Ischemia; NA = not applicable or not available.

emergency department and their median stroke scale scores, concluding that only $5 \%$ to $13 \%$ of patients may be eligible for intra-arterial thrombolytic therapy. This would translate to 34,000 to 87,750 patients annually, on the basis of a total of 675,000 AIS patients.

Table 2 summarizes the estimates of AIS patients who may be eligible for endovascular therapy according to the previously described methods.

Estimating the workforce. The workforce is the number of NIs needed to provide continuous coverage, given a specific demand, within a geographic radius. It is assumed that specialists provide $24 / 7$ coverage and will be able to serve a reasonable geographic radius (approximately 50 miles) that would allow for patient transfer in a timely manner. This number of NIs is dependent on a balance between a sufficient case volume to maintain proficiency and an overwhelming case volume that leads to provider fatigue. Therefore, proficiency criteria are needed to define this balance. Data on the minimum volume of cases required for NIs to maintain competency are lacking.

The mean range estimate of AIS patients eligible for endovascular therapy is 27,000 to 97,000 patients. If we divide the number of projected cases requiring endovascular therapy by the current estimated number of fellowship-trained NIs (800), it would translate to 34 to 121 cases per each NI. This estimate of the annual number of cases per practitioner would be lower $(27$ to 97 ) if the number of NIs were closer to 1,000 , or even as low as 23 to 81 if the number of NIs were 1,200 .

Hospital locations were geocoded in ArcGIS (Esri, Redlands, CA) with use of the Esri Street Map US Street Addresses locator. To generate the maps in the figure, we used ArcGIS as well as geographic boundaries for US states and counties from Esri to calculate 20-, 50-, and 70-mile radius buffers around each hospi- tal location. The figure (B, C, and D) depicts the number of NIs per state and their coverage area; note that most of the densely populated regions of the United States are covered by at least 1 NI within the accessible area, defined above as a 50-mile radius (the maps also indicate the different circles of 50- and 70-mile radii with at least 1,2 , or $3 \mathrm{NIs}$ ). The maps illustrate higher density in the more populated areas, which seems to be logical since NIs tend to look for areas where they can maintain their skills in other neurointerventional procedures, which is necessary to perform AIS intervention at a high skill level. Coverage 24/7 with at least 3 NIs providing AIS endovascular therapy at a given center was lagging in many states, as shown in the figure, $\mathrm{D}$. This may be why NIs are getting help from diagnostic neuroradiologists and peripheral/body interventionalists to increase the flexibility in providing $24 / 7$ coverage, which is not accounted for in the maps.

DISCUSSION No data are available to provide an accurate estimate of the demand and supply for AIS endovascular therapy. Our estimates are based on published data on epidemiologic and endovascular therapy as well as several assumptions, which enabled us to come up with various ranges of AIS cases potentially eligible for such therapy. Based on our estimate and the methods used in this article, between 27,000 and 96,000 AIS patients annually ( $4 \%$ to $14 \%$ of all patients with ischemic stroke) may be eligible for AIS endovascular therapy.

Our estimates of potential cases used 3 methods: the first was population-based, the second relied on endovascular therapy clinical trials, and the third used local and regional registries, including our own practice at the Medical College of Wisconsin. The mean estimate is that $4 \%$ to $14 \%$ of all AIS cases (or 27,000 to 97,000 ) may be eligible for endovascular therapy. It is less likely to reach the upper limit and may be closer to the midpoint of 50,000, which is close to the estimate obtained by other authors who reported that the number of cases needing AIS endovascular therapy is close to 40,000 annually. ${ }^{24,25}$ If these numbers are true and the number of hospitals in the United States is close to 6,000 (per the American Hospital Association), it would yield a rate of 4 to 16 cases per hospital annually, which may dilute technical experience and lead to less than favorable outcomes.

If we are going to have this maximum number of cases, do we have enough NIs to provide such coverage with 24/7 availability, acceptable training, and accessibility (within a 50-mile radius)? In 2004, a report on the manpower for intra-arterial therapy in the United States estimated that $99 \%$ of the US population in 2001 lived within a 200-mile radius of at least 1 of the 385 NIs active at that time. ${ }^{26}$ The majority of SVIN roundtable attendees believed that the minimum number of AIS endovascular therapy cases necessary for maintaining skills is 12 per year, or 1 every month, given that interventionalists have ade- 
Table 2 Summary of estimated numbers of ischemic strokes eligible for endovascular therapy

\begin{tabular}{|c|c|c|c|}
\hline $\begin{array}{l}\text { Basis for estimation of endovascular } \\
\text { AIS annual case volume estimates }\end{array}$ & $\begin{array}{l}\text { Percentage of all } \\
\text { AIS cases, range }\end{array}$ & Lower-end no. (SD) & Upper-end no. (SD) \\
\hline US population-based, large-vessel disease & 9 to 27 & 60,750 & 18,2250 \\
\hline $\begin{array}{l}\text { Prospective endovascular AIS trial screening } \\
\text { data, screened vs enrolled }\end{array}$ & 1.5 to 10.7 & 11,000 & 75,000 \\
\hline $\begin{array}{l}\text { Regional and hospital registry based, } \\
\text { large-vessel disease and severe stroke }\end{array}$ & 5 to 13 & 34,000 & 87,750 \\
\hline $\begin{array}{l}\text { Hirsch et al. (2009), } 500 \text { hospitals performing } \\
\text { at MG or St. Luke center } \text { volume }^{25}\end{array}$ & 1.5 to 6.2 & 10,400 & 41,500 \\
\hline Cloft et al. (2009) ${ }^{24}$ & 3 to 18.7 & 20,000 & 120,000 \\
\hline National Inpatient Sample Database $2008^{31}$ & 2 & 14,000 & \\
\hline $\begin{array}{l}\text { Medical College of Wisconsin }(3 \mathrm{NIs}, 2005= \\
24 / 540 \text { to } 2009=64 / 630)\end{array}$ & 4.4 to 10.2 & 30,000 & 68,571 \\
\hline \multicolumn{4}{|l|}{ Mean (SD) } \\
\hline Lower range & $3.6(2.6)^{b}$ & $25,736(17,960)$ & $96,845(50,133)$ \\
\hline Upper range & $14.3(7.4)^{c}$ & & \\
\hline \multicolumn{4}{|l|}{ No. of cases/y per $\mathrm{NI}$, assuming $\mathrm{NI}$ total is } \\
\hline 800 & & $32(25,736 / 800)$ & $121(96,845 / 800)$ \\
\hline 1,000 & & $26(25,736 / 1,000)$ & $97(96,845 / 1,000)$ \\
\hline 1,200 & & $22(25,736 / 1,200)$ & $81(96,845 / 1,200)$ \\
\hline
\end{tabular}

Abbreviations: $\mathrm{AIS}=$ acute ischemic stroke; $\mathrm{Cl}=$ confidence interval; $\mathrm{NI}=$ neurointerventionalist.

a Massachusetts General Hospital and St. Luke's Brain and Stroke Institute, Boston.

b $95 \% \mathrm{Cl}=0.9-6.3$.

c $95 \% \mathrm{Cl}=6.5-22.1$.

quate numbers of diagnostic cerebral angiograms. Training standards vary according to different societies and range from 30 to 100 diagnostic cerebral angiograms. ${ }^{27,28}$ Ideally, as per neurovascular AIS intervention training standards, all NIs should be fellowship-trained. ${ }^{29}$

Allowing several operators to perform AIS intervention, merely to provide $24 / 7$ coverage and address the workforce need-with variability in comfort level, extent of training, and background-may deter some neurologists from referring AIS patients for endovascular therapy. How to address the workforce needs if the future demand for AIS endovascular therapy increases remains a controversial question. The size of the NI workforce is influenced by a complex set of factors, including training standards, institutional policies, and individual decisions. Furthermore, maintaining proficiency in highly skilled neurointerventional techniques and clinical decision-making demands a judicious case-volume balance.

This study is limited by the described assumptions and lack of prospective population-based data on AIS endovascular therapy. In particular, demand estimates from clinical trials may be difficult to establish because of the variability in trial inclusion and exclusion criteria. The upper range in our report may be an overestimate, given the data from one European registry with a tertiary centralized care system and $0.7 \%$ rate of endovascular therapy, ${ }^{22}$ and the low rate of IV alteplase use, which is $2 \%$ of eligible patients in most countries and $1 \%$ to $8 \%$ in the United States and Europe. ${ }^{30}$ Another limitation concerns estimating the demand from the incidence data of stroke and reporting the findings as simple percentages, which may not be accurate as these are crude estimates. In addition to the aforementioned limitations, we did not account for the hypothetical increase in demand with an aging population. Moreover, the results of randomized clinical trials may increase or decrease the number of patients eligible for endovascular AIS therapy. The manpower estimate is limited by the significant number of AIS interventions performed by experienced general interventional radiologists. Their exact number is not known, but they may provide an additional workforce that can be maximized if demand increases.

The workforce of skilled NIs is estimated to be adequate to meet the current demands of endovascular AIS therapy. However, these estimates lack largepopulation-based data on endovascular therapy for AIS. Estimating the future demand is challenging due to the dynamic field of acute stroke intervention. The demand for endovascular therapy in patients with AIS will likely increase because of an expanding and aging population and advances in patient selection and device technology. Innovative triage solutions, such as comprehensive stroke center systems similar to a trauma model, may improve safe and 
effective delivery of endovascular therapy for patients with acute ischemic stroke. However, consideration must be given to the balance between the optimal case volume to provide skillful, high-quality manpower and avoiding fatigue among primary operators.

\section{AUTHOR CONTRIBUTIONS}

All authors participated in the design, writing, and editing of the final version of the manuscript.

\section{DISCLOSURE}

Dr. Zaidat serves on the scientific advisory board for Talecris; served on the adjudication committee for Stryker; received speaker honoraria from Stryker; served on the editorial board of Frontiers in Neurology (Endovascular \& Interventional Neurology Section); serves as Editor of the Journal of Neurointerventional Surgery and serves as Associate Editor and is a member of the Editorial Board of Journal of Stroke \& Cerebrovascular Diseases; served as a consultant for Stryker Neurovascular-Commercial, Codman Neurovascular-Commercial, and Microvention Inc.-Commercial; and has received research support from a Society of Vascular \& Interventional Neurology (SVIN) grant for this educational activity. Dr. Lazzaro and Ms. McGinley report no disclosures. Dr. Edgell serves as an Associate Editor of Frontiers of Interventional Neurology. Dr. Nguyen serves as Associate Editor of Frontiers of Vascular and Interventional Neurology and Editor of SVIN newsletter The Core; performs intra-arterial stroke procedures; and serves as a consultant for Penumbra. Dr. Linfante served as a consultant for Codman Neurovascular and Stryker; holds stock options in Surpass Limited; serves on the Scientific Advisory Board for Codman Neurovascular; serves on the editorial boards for Stroke and Journal of Neurointerventional Surgery; and serves on the speakers bureau for Codman. Dr. Janjua serves on the scientific advisory board for Lundbeck/ DSMB and Neurointerventions; receives research support from NIH/ NINDS; and holds stock or stock options or Board of Directors compensation for Neurointerventions. Go to Neurology.org for full disclosures.

Received June 28, 2011. Accepted in final form December 1, 2011.

\section{REFERENCES}

1. Ginsberg MD. The validity of rodent brain-ischemia models is self-evident. Arch Neurol 1996;53:1065-1066.

2. Del Zoppo GJ, Levy D, Broderick JP. Thrombolytic therapy in the treatment of stroke. Drugs 1997;54(suppl 3):90-99.

3. Saver JL. Time is brain: quantified. Stroke 2006;37:263266.

4. Furlan A, Higashida R, Wechsler L, et al. Intra-arterial prourokinase for acute ischemic stroke: the PROACT II study: a randomized controlled trial: Prolyse in Acute Cerebral Thromboembolism. JAMA 1999;282:2003-2011.

5. Ogawa A, Mori E, Minematsu K, et al; MELT Japan Study Group. Randomized trial of intraarterial infusion of urokinase within 6 hours of middle cerebral artery stroke: the Middle Cerebral Artery Embolism Local Fibrinolytic Intervention Trial (MELT) Japan. Stroke 2007;38:26332639.

6. IMS II Trial Investigators. The International Management of Stroke (IMS) II Study. Stroke 2007;38:2127-2135.

7. Trial and Cost Effectiveness Evaluation of Intra-arterial Thrombectomy in Acute Ischemic Stroke (THRACE). Available at: http://clinicaltrials.gov/ct2/show/NCT01062698. Accessed February 2012.

8. Baron JC. Mapping the ischaemic penumbra with PET: implications for acute stroke treatment. Cerebrovasc Dis 1999;9:193-201.
9. Darby DG, Barber PA, Gerraty RP, et al. Pathophysiological topography of acute ischemia by combined diffusionweighted and perfusion MRI. Stroke 1999;30:2043-2052.

10. Barber PA, Darby DG, Desmond PM, et al. Prediction of stroke outcome with echoplanar perfusion- and diffusionweighted MRI. Neurology 1998;51:418-426.

11. Khatri P, Abruzzo T, Yeatts SD, Nichols C, Broderick JP, Tomsick TA. Good clinical outcome after ischemic stroke with successful revascularization is time-dependent. Neurology 2009;73:1066-1072.

12. Cumulative estimates of resident population change for the United States, states, counties, Puerto Rico, and Puerto Rico Municipios: April 1, 2000 to July 1, 2009. US Census Bureau, Population Division: 2010.

13. Lloyd-Jones D, Adams RJ, Brown TM, et al. Heart disease and stroke statistics: 2010 update: a report from the American Heart Association. Circulation 2010;121:e46-e215.

14. Lloyd-Jones D, Adams R, Carnethon M, et al. Heart disease and stroke statistics: 2009 update: a report from the American Heart Association Statistics Committee and Stroke Statistics Subcommittee. Circulation 2009;119: 480

15. Lanska DJ. Geographic distribution of stroke mortality in the United States: 1939-1941 to 1979-1981. Neurology 1993;43:1839-1851.

16. Wolfe AP. Epidemiology of stroke. In: Mohr JP, Choi DW, Grotta JC. Stroke: Pathophysiology, Diagnosis, and Management, 4th ed. New York: Churchill Livingstone; 2004:13-34.

17. del Zoppo GJ, Higashida RT, Furlan AJ, et al. PROACT: A Phase II Randomized Trial of Recombinant ProUrokinase by Direct Arterial Delivery in Acute Middle Cerebral Artery Stroke. Stroke 1998;29:4-11.

18. Smith WS, Sung G, Starkman S, et al, for the MERCI Trial Investigators. Safety and efficacy of mechanical embolectomy in acute ischemic stroke: results of the MERCI trial. Stroke 2005;36:1432-1438.

19. Smith WS, Sung G, Saver J, et al., for the Multi MERCI investigators. Mechanical thrombectomy for acute ischemic stroke: final results of the Multi MERCI Trial. Stroke 2008;39:1205-1212.

20. The Penumbra Pivotal Stroke Trial Investigators. The Penumbra Pivotal Stroke Trial: safety and effectiveness of a new generation of mechanical devices for clot removal in intracranial large vessel occlusive disease. Stroke 2009; 40: 2761-2768.

21. Barber PA, Zhang J, Demchuk AM, Hill MD, Buchan AM. Why are stroke patients excluded from TPA therapy? An analysis of patient eligibility. Neurology 2001;56: 1015-1020.

22. Bhatia R, Hill MD, Shobha N, et al. Low rates of acute recanalization with intravenous recombinant tissue plasminogen activator in ischemic stroke: real-world experience and a call for action. Stroke 2010;41:2254-2258.

23. Michel P, Odier C, Rutgers M, et al. The Acute STroke Registry and Analysis of Lausanne (ASTRAL): design and baseline analysis of an ischemic stroke registry including acute multimodal imaging. Stroke 2010;41:2491-2498.

24. Cloft HJ, Rabinstein A, Lanzino G, Kallmes DF. Intraarterial stroke therapy: an assessment of demand and available work force. AJNR Am J Neuroradiol 2009;30: 453-458. 
25. Hirsch JA, Yoo JA, Nogueira RG, et al. Case volume of intra-arterial and intravenous treatment of ischemic stroke in the USA. J NeuroInterv Surg 2009;1:27-31.

26. Suzuki S, Saver JL, Scott P, et al. Access to intra-arterial therapies for acute ischemic stroke: an analysis of the US population. AJNR Am J Neuroradiol 2004;25:18021806.

27. Connors JJ 3rd, Sacks D, Furlan AJ, et al. NeuroVascular Coalition Writing Group: training, competency, and credentialing standards for diagnostic cervicocerebral angiography, carotid stenting, and cerebrovascular intervention: a joint statement from the American Academy of Neurology, the American Association of Neurological Surgeons, the American Society of Interventional and Therapeutic Neuroradiology, the American Society of Neuroradiology, the Congress of Neurological Surgeons, the AANS/CNS Cerebrovascular Section, and the Society of Interventional Radiology. Neurology 2005;64:190-198.

28. Rosenfield K, Babb JD, Cates CU, et al. Clinical competence statement on carotid stenting: training and creden- tialing for carotid stenting: multispecialty consensus recommendations: a report of the SCAI/SVMB/SVS Writing Committee to develop a clinical competence statement on carotid interventions. J Am Coll Cardiol 2005;45:165174 .

29. Meyers PM, Schumacher HC, Alexander MJ, et al; Writing Group for American Academy of Neurology, American Association of Neurological Surgeons Cerebrovascular Section, Society of Neurointerventional Surgery, and Society of Vascular and Interventional Neurology. Performance and training standards for endovascular ischemic stroke treatment. J Stroke Cerebrovasc Dis 2009;18:411415 .

30. Hacke W, Kaste M, Bluhmki E, et al. Thrombolysis with Alteplase 3 to 4.5 hours after acute ischemic stroke. N Engl J Med 2008;359:1317-1329.

31. Brinjikji W, Rabinstein AA, Kallmes DF, Cloft HJ. Patient outcomes with endovascular embolectomy therapy for acute ischemic stroke: a study of the National Inpatient Sample: 2006 to 2008. Stroke Epub 2011 Apr 14. 


\section{Neurology}

\section{Demand-supply of neurointerventionalists for endovascular ischemic stroke therapy Osama O. Zaidat, Marc Lazzaro, Emily McGinley, et al. Neurology 2012;79; $335-\mathrm{S} 41$ \\ DOI 10.1212/WNL.0b013e31826957ef}

This information is current as of September 24, 2012

\section{Updated Information \&} Services

References

Citations

Subspecialty Collections

Permissions \& Licensing

Reprints including high resolution figures, can be found at: http://n.neurology.org/content/79/13_Supplement_1/S35.full

This article cites 27 articles, 18 of which you can access for free at: http://n.neurology.org/content/79/13_Supplement_1/S35.full\#ref-list-1

This article has been cited by 1 HighWire-hosted articles: http://n.neurology.org/content/79/13_Supplement_1/S35.full\#\#otherarti cles

This article, along with others on similar topics, appears in the following collection(s):

\section{All Cerebrovascular disease/Stroke}

http://n.neurology.org/cgi/collection/all_cerebrovascular_disease_strok e

\section{All epidemiology}

http://n.neurology.org/cgi/collection/all_epidemiology

Information about reproducing this article in parts (figures,tables) or in its entirety can be found online at:

http://www.neurology.org/about/about_the_journal\#permissions

Information about ordering reprints can be found online: http://n.neurology.org/subscribers/advertise

Neurology ${ }^{\circledR}$ is the official journal of the American Academy of Neurology. Published continuously since 1951, it is now a weekly with 48 issues per year. Copyright Copyright $(0) 2012$ by AAN Enterprises, Inc.. All rights reserved. Print ISSN: 0028-3878. Online ISSN: 1526-632X.

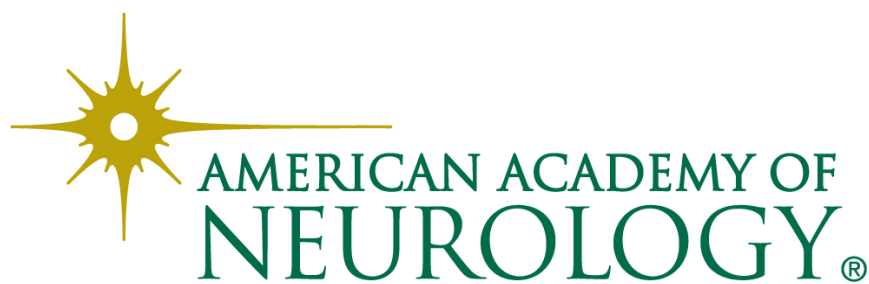

